\title{
DESIGN OF ELECTRONICALLY CONTROLLED FUEL INJECTION SYSTEM FOR CARBURETOR BASED ENGINE
}

\author{
Abhishek Kumar ${ }^{1}$, Abhijeet Kumar ${ }^{2}$, Ujjwal Ashish $^{3}$, Ashok B ${ }^{4}$ \\ ${ }^{1}$ B.Tech (EEE), $3^{\text {rd }}$ year, VIT University, Vellore, India \\ ${ }^{2}$ B.Tech (ECE), $3^{\text {rd }}$ year, VIT University, Vellore, India \\ ${ }^{3}$ B.Tech (EEE), $3^{\text {rd }}$ year, VIT University, Vellore, India \\ ${ }^{4}$ Assistant Professor, SMBS, VIT University, Vellore, India
}

\begin{abstract}
In the Modern world, automotive electronics play an important role in the manufacturing of any passenger car. Automotive electronics consists of advanced sensors, control units, and "mechatronic"actuator making it increasingly complex, networked vehicle systems. Electronic fuel injection (EFI) is the most common example of automotive electronics application in Powertrain. An EFI system is basically developed for the control of injection timing and fuel quantity for better fuel efficiency and power output. In this paper, we will explain various types of fuel injection system that are used most commonly nowadays and will also explain the various parameters considered during calculating,(using speed density method), base fuel quantity during runtime. We will explain the major difference between speed density method and alpha-n method and in the end, we will also show the MATLAB/Simulink model of fuel injection system for Single cylinder four stroke engine.
\end{abstract}

Keywords: Air Fuel Ratio, Fuel Injection System, Speed Density Method, Engine Management System

\section{INTRODUCTION}

Engine management system (EMS) is an essential part of any vehicle, which controls and monitors the engine. Although many other functions are also catered by EMS but usually it is a custom built computer which is responsible for the running of an engine by monitoring the engine RPM, load and temperature and initiating the ignition at the right time for the prevailing conditions and controlling the flow of fuel to the engine in the exact quantity as required. Embedded controllers are used for the implementation of engine management systems known as Engine control unit (ECU).

In modern world electronic controls are used almost in every major domain of automobile. Therefore, the number of ECUs in a vehicle have increased abruptly as compared to the last 10 years. One of the major advantages of using Electronics for controlling fuel injection is precise control and timing of injector which leads to increase in the performance of the engine. Modern electronics has reached that level of advancement that it can precisely perform its functions whilst ensuring better efficiency and performance. They are extremely reliable and require very less maintenance. $[1,2]$

\subsection{Fuel Injection system}

It is the most important part of the powertrain of an automobile. Fuel Injection system basically calculates the amount of fuel that is needed to be injected inside the engine cylinder based on various engine parameters. Electronic fuel injection replaced the Carburetor in early 1980's.
The primary difference between carburetors and fuel injection system is that fuel injection atomizes through a small nozzle under high pressure while a carburetor relies on suction created by intake air, accelerated through a venturi tube to draw the fuel into the air stream.

From the figure given below (fig. 1 and fig. 2) basic principle behind the working of both the systems has been explained.

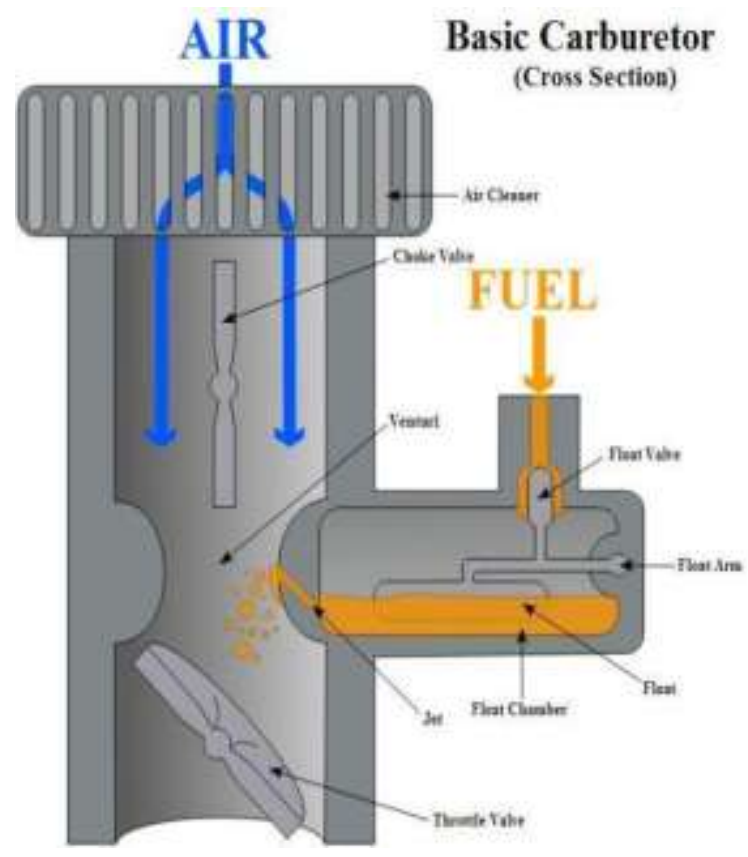

Figure1: Basic Carburetor 


\section{Advantage of EFI over Carburetor}

In early days, Automobile Industry mostly used carburetor because of its simple working and more reliability as compared to electronics circuits present at that time, but after the development of semiconductor and silicon circuits all the major industries shifted toward electronics chips because of their fast and robust processing.

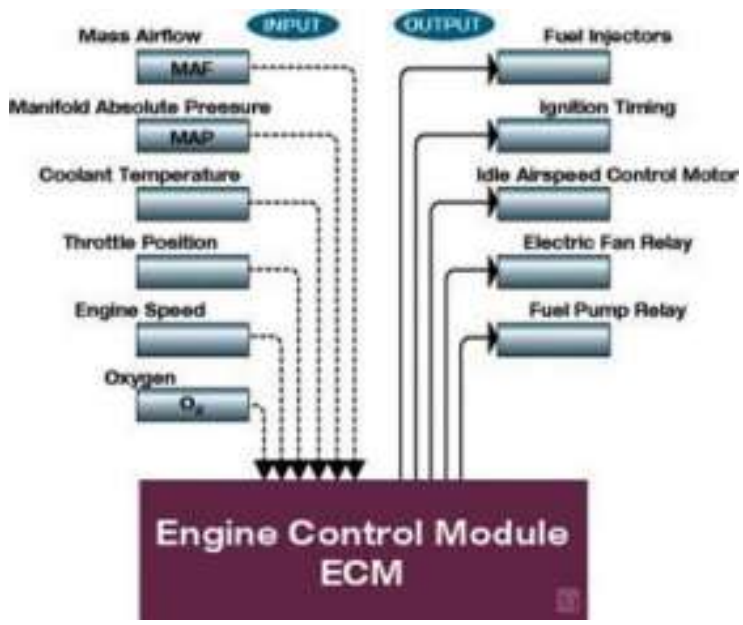

Figure 2: Block diagram Of EFI

\section{Speed Density Method}

Speed density method is used for estimating airflow into an engine in order to supply an appropriate amount of fuel and adequate spark timing.

Sensors most commonly used in Speed density method are mainly MAP, TPS, IAT, O2 sensor (lambda sensor) and Hall Effect.

Theoretical basis for the speed density method is ideal gas law

$$
\mathrm{n}=(\eta) \mathrm{PV} / \mathrm{RT}
$$

where,

$\mathrm{P}=$ Intake Pressure (MAP Sensor

reading) $\quad \mathrm{V}=$ Volume, Engine

displacement $\mathrm{R}=$ Ideal Gas Constant

$\eta=$ Volumetric Efficiency

$\mathrm{T}=$ Intake Temperature (Intake air temp. sensor) and $n=$ no. of moles of gas present inside the intake.

and we know that,

$$
\mathrm{AFR}=\frac{\text { mass of } \text { air }}{\text { mass of } f u \in l}
$$

AFR at stoichiometric condition is 14.7

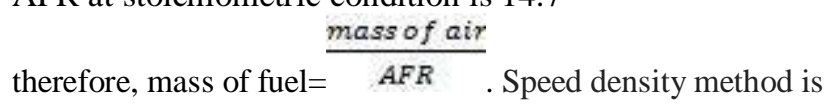
mostly used as it is compatible to almost all engine conditions like cold start etc. The most important reason behind using speed density method is that, MAP sensor is extremely responsive and it gives a better result as compared to Mass-Air flow Method. There are several other approaches used to calculate base fuel quantity, such as Alpha-n method. This method only uses readings from the TPS sensor and engine RPM. This method is mostly used to calculate base fuel quantity in all the tricky situations like Wide Open Throttle (WOT). Here, MAP sensor fails to sense accurate intake pressure, which leads to an error in base fuel quantity. $[1,2,3]$

In this paper, we mostly focus on Developing Electronic Fuel Injection for a carb based engine i.e. Honda GX 35cc (4 stroke, Single Cylinder Engine). Firstly we will focus ourselves on various theories and approaches to calculate base fuel consumption of an engine and then we will try to minimize the various errors such as wall wetting and injector lag, etc. in order to make the system more accurate and robust.

\subsection{Model-Based Design}

For Designing of 4 Stroke single cylinder engine, we went through various research works which are already published in the past related to Air/Fuel ratio (AFR) [1].

For simulating the IC engine, we used Mean Value Engine Model. It is based on the ideal gas law, and is mostly used for engine analysis. Through the model, various specifications such as crankshaft rotation, overall power, fuel consumption and intake manifold are explained. In addition to these parameters, mean value change of thermal efficiency and volumetric efficiency with respect to time are also explained.

\section{(1) Throttle body Model}

(2) Air Intake Model

Throttle body model- It plays an important role in calculating the airflow through throttle body. Input to this model is throttle angle and we get mass flow rate as the output.

Mass flow rate through the body is represented by MAF:

$\mathrm{MAF}=\operatorname{mat} 0+\frac{\operatorname{mat} 1 * \mathrm{~Pa} * \mathrm{f}(\Theta) * \mathrm{~g}(\mathrm{pr})}{\sqrt{\mathrm{Ta}}}$

where,

$\mathrm{f}(\Theta)$->Functional relation between throttle angle and Mass flow rate.

$\mathrm{g}(\mathrm{Pr})->$ Relationship between atmospheric pressure, Patm and Intake pressure, Pintake.

$$
\begin{aligned}
& \operatorname{Pr}=(\text { Pintake/Patm }) \\
& g(\operatorname{Pr})= \begin{cases}\sqrt{1-\frac{P r-0.4125}{1-0.4125}} & \operatorname{Pr} \geq 0.450\end{cases}
\end{aligned}
$$

MAF -> Air flow rate, $\mathrm{Kg} / \mathrm{S}$; 
$=$ Throttle angle (in ${ }^{\circ}$;

Patm and Pintake $=$ pressure;

mat 1 and mat $0=$ Intake constant;

$\mathrm{Ta}=$ Temperature in Kelvin $(\mathrm{K})$

Air Intake model- It uses air flow, MAF and engine speed as the input. It uses the current intake manifold condition as the parameter and it has air flow into the engine cylinder MAP as the output of the system.

\section{$M^{\prime}$ i=M' af-M ap}

M'at and M'ap represents air flow rate through throttle and air flow rate through engine cylinder respectively, $\mathrm{Kg} / \mathrm{S}$.

M'ap $^{\prime}=\frac{\mathrm{Vd} *\left(\mathrm{nv} * \mathrm{P}_{\text {intake }}\right) * \mathrm{n}}{120 * \mathrm{R} * \mathrm{Ti}}$

Where

$\mathrm{Vd}=$ Volume of the Engine, L (In this case 35cc) $\mathrm{nv}=$ Volumetric efficiency of the Engine

$\mathrm{R}=$ Ideal Gas Constant $\mathrm{Ti}=$ Intake Temperature, Kelvin $\mathrm{n}=$ Engine speed, $\mathrm{r} / \mathrm{min}$

Subsequent to the improvement of exact model of volumetric effectiveness is troublesome. Keeping in mind the end goal and to make things simpler we have used the general formula, which is as follows-

$\mathrm{nv} *$ Pintake $=\mathrm{A}(\mathrm{n}) *$ Pintake $+\mathrm{B}(\mathrm{n})$

$A(n), B(n)$ are the expression about the engine speed.

Therefore,

$$
\text { MAP }=\frac{V d * n * A(n) * P_{\text {intake }}+B(n)}{120 * R * T i}
$$

\subsection{Fuel Injection Model}

It represents needle opening time each cycle. Fuel injection pulse width straightforwardly relies on fuel quantity of each cylinder in each cycle and on the injection parameter.

Input to the model is air mass ratio into the cylinder and stoichiometric. Fuel injection model is the output.

Fuel Injection Pulse width is given by

$\mathrm{Q}=\mathrm{MAP} /(\mathrm{a} / \mathrm{f})$

$\mathrm{Tp}=\mathrm{Q} / \mathrm{S}$

$\mathrm{a} / \mathrm{f}$ is air fuel ratio
Tp is Base Injection Pulse $(\mathrm{mS})$

Q is flow rate of fuel into the cylinder of the engine for any operating conditions, $\mathrm{g} / \mathrm{s}$

Where $\mathrm{S}$ is specific parameter of Injector calculated by,

$\mathrm{S}=\mu f \sqrt{2 \rho g\left(P_{\text {fuel }}-P_{\text {intake }}\right)}$

$\mu=$ flow co-eff.

$\mathrm{f}=$ nozzle cross-sectional area $\mathrm{g}=$ gravitational acceleration on Earth $\rho=$ Fuel Density

pfuel $=$ Pressure exerted by fuel pintake $=$ Intake Pressure

Therefore,

$\mathrm{Tp}=\frac{\text { M'ap }}{\left(\frac{\mathrm{a}}{\mathrm{f}}\right) * \mu \mathrm{f} \sqrt{2 \rho \mathrm{g}(\mathrm{pf}-\mathrm{pi})}}$

\section{MATLAB Simulations}

After Various iterations and research we finally got a 2-D graph of the various engine parameters, which are mostly used in designing and analysis (Tuning) of electronic control unit. Here is the screenshot of the Simulink Scope Display.

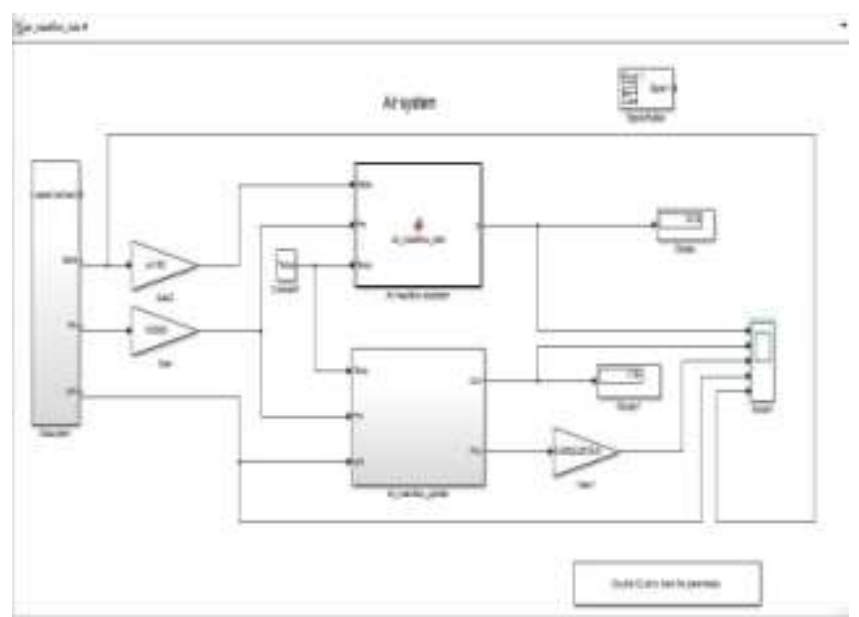

Fig 3.Simulink Model for Single Cylinder 4 stroke Engine

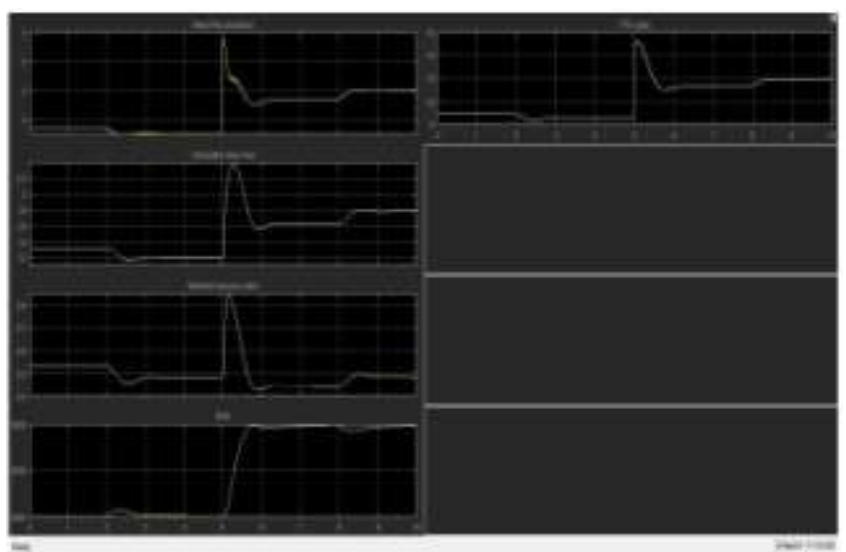

Fig 4: Graphical display of various engine parameter 


\section{Experiment (Designing of ECU)}

It can be easily inferred from the simulation that EFI can be designed for single cylinder four stroke engine(Honda gx35cc engine).This ECU can be easily interfaced with ecotrons sensor which can be easily tuned to run in stoichiometric AFR(i.e. 14.7).

\section{CONCLUSION}

It can be easily concluded from the above experiment that EFI can be designed for single cylinder small engine to increase its engine performance and overall efficiency. However, abnormal behavior of the four stroke $35 \mathrm{cc}$ engine is observed in idle conditions. We observe an oscillation in engine RPM from the range of 2500 to 5000 (Honda GX35CC engine). However this abnormal behavior can be reduced by CDI control.

\section{ACKNOWLEDGMENTS}

We would like to thanks Team Eco Titans, VIT University for their continuous help and support.

\section{REFERENCES}

[1] Simulation of the original injection map diagram of electronic-controlled gasoline engines based on MATLAB/SIMULINK - Tianyu zhu, Haiqiao wei , Jian zhao -State key laboratory of engines tianjin university Tianjin, china

[2] Adaptive air fuel ratio control for internal combustion engines -Y. Yildiz, student member, ieee, A. Annaswamy, fellow, IEEE, D. Yanakiev, member, IEEE, I. Kolmanovsky, fellow, IEEE

[3] Application of input estimation techniques to charge estimation and control in automotive engines-alexander stotsky, ilya kolmanovsky

\section{BIOGRAPHIES}

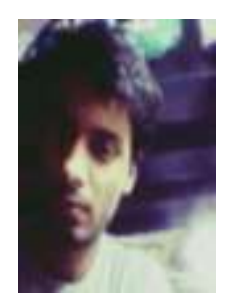

Abhijeet Kumar is doing his B.Tech In Electronics and communication Engineering from VIT University, Vellore. He also designed a low cost and open source design to detect dyslexia in children under TIFAC, DST, and Govt. Of India. His area of interest is Signal Processing and Brain Computer Interface

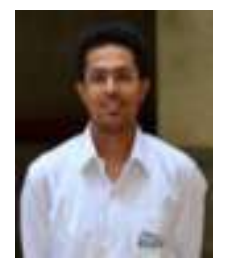

Ujjwal Ashish is doing his B. Tech in Electrical and Electronics engineering from VIT University, Vellore. He along with his team represented India and VIT University represented in Formula Student, Germany2015.His main are of interest is Power systems, Embedded system.

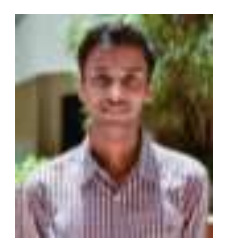

Abhishek Kumar is doing his B.Tech in Electrical and Electronics engineering from VIT University, Vellore. His main area of interest is Automotive Electronics, Control System.

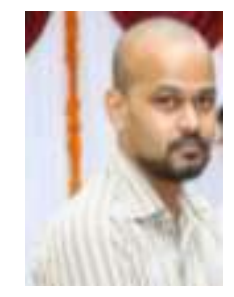

Professor Ashok B. is working as Assistant professor in VIT university, Vellore. His main area of interest is Automotive electronics, Control system and IC engine. 